\title{
Enjeksiyon Edilmiş Plastiğin Soğutulması İşleminin Optimizasyon Çalışması
}

\author{
Burak Türkan* \\ Bursa Uludağ Üniversitesi, Gemlik Asım Kocabıyık MYO, Makine Bölümü, Bursa, Türkiye, (ORCID: 0000-0002-4019-7835), burakt@uludag.edu.tr
}

(İlk Geliş Tarihi 16 Ekim 2021 ve Kabul Tarihi 27 Aralık 2021)

(DOI: $10.31590 /$ ejosat.1010170)

\begin{abstract}
ATIF/REFERENCE: Turkan, B. (2021). Enjeksiyon Edilmiş Plastiğin Soğutulması İşleminin Optimizasyon Çalışması. Avrupa Bilim
\end{abstract} ve Teknoloji Dergisi, (31), 801-808.

\section{$\ddot{O} \mathbf{z}$}

Kalıp içi soğutma işlemlerinde kullanılan simülasyon metodu ile optimum koşulların tespit edilmesi maliyet, süre ve üründe oluşabilecek çatlak ve gerilme riskinin tespiti açısından ciddi bir öneme sahiptir. Bu çalışmada enjeksiyon edilmiş plastiğin soğutulması sürecinin optimizasyon çalışması incelenmiştir. Comsol programı yardımı ile simülasyon metodu kullanılarak optimizasyon çalışması yapılmıştır. Soğutma işleminde farklı parametrelerin (akışkan debisi, yüzey pürüzlülük değeri, kanal içi çap) ürün soğutulması üzerindeki etki yüzdeleri hesaplanmıştır. Optimum soğutma koşulları, yüzey pürüzlülük değeri 2.5 mm, akışkan debisi 81t/dk ve kanal çapı $1 \mathrm{~cm}$ olarak elde edilmiştir. Soğutma işleminde en fazla katkıyı akışkan debisi (\%83) sağlamıştır. Optimum koşulda kalıbın 300 saniyede $170^{\circ} \mathrm{C}$ soğuduğu görülmüştür. Sonuç olarak pürüzlülük ve debinin artışı ile kalıbın daha kısa sürede soğuduğu tespit edilmiştir. Ancak kanal çapının artışı ile kalıbın daha geç soğuduğu gözlenmiştir. Son olarak analizden elde edilen sonuçlar ile Taguchi analizinin doğrulama çalışması yapılmıştır.

Anahtar Kelimeler: Comsol, Soğutma, Enjeksiyon kalıbı, Taguchi, Optimizasyon.

\section{Optimization Study of The Process of Cooling Injected Plastic}

\begin{abstract}
Determining the optimum conditions with the simulation method used in in-mold cooling processes has a serious importance in terms of cost, time and determination of the risk of cracks and stress that may occur in the product. In this study, the optimization study of the cooling process of the injected plastic was investigated. Optimization study was carried out by using simulation method with the help of Comsol program. The effect percentages of different parameters (fluid flow rate, surface roughness value, channel diameter) on product cooling in the cooling process were calculated. Optimum cooling conditions were obtained as surface roughness value of $2.5 \mathrm{~mm}$, fluid flow rate of $81 \mathrm{t} / \mathrm{min}$ and channel diameter of $1 \mathrm{~cm}$. Fluid flow rate $(83 \%)$ contributed the most in the cooling process. It was observed that the mold cooled to $170{ }^{\circ} \mathrm{C}$ in 300 seconds under the optimum condition. As a result, it was determined that the mold cooled in a shorter time with the increase of roughness and flow rate. However, it was observed that with the increase of the channel diameter, the mold cooled down later. Finally, the validation study of Taguchi analysis was carried out with the results obtained from the analysis.
\end{abstract}

Keywords: Comsol, Cooling, Injection mold, Taguchi, Optimization.

*Sorumlu Yazar: burakt@uludag.edu.tr 


\section{Giriş}

Plastikler hafif, dayanıklı ve kolay şekillendirilebilir olmaları nedeniyle çok çeşitli alanlarda kullanılan malzemelerdir. Düşük maliyetlerine ek olarak, plastikleri benzersiz kılan birçok değerli parçaya dönüştürülebilirler. Polimer olarak da adlandırılır ve farklı polimer zincirlerinden oluşan plastikler günlük hayatımızın hemen her alanında farklı form ve yapılarda bulunur (Timur ve Kılıç, 2021)

Plastik malzemesinin enjeksiyon kalıplanma işlemi paketleme ve soğutma gibi birkaç aşamadan oluşur. Soğutma sistemi tasarımı, çevrim süresinin yaklaşık \%80'i soğutma aşaması tarafından alındığından oldukça önemlidir. Plastik parçanın bozulmadan dişarı atılabilmesi için soğutma sistemi 1sıyı gerekli oranda uzaklaştırabilmelidir. Aynı zamanda termal gerilme gibi istenmeyen kusurların azaltılabilmesi için parçanın soğutulması mümkün olduğunca üniform ve dengeli tutulmalıdır (Qiao, 2006).

Plastik enjeksiyon kalıplama işlemi, termoplastik malzemenin her iki kalıp boşluğunun oluşturduğu kısma yüksek sıcaklıkta enjeksiyonu ile başlamaktadır. Kalıp içine girdikten sonra plastik sıkıştırılır, parçanın geometrisinin deformasyon olmadan korunmasını sağlayan katılaşma sıcaklığını elde edene kadar soğutulur. Kalıplama döngüsünün süresi, kalıbın metal malzemesi boyunca 1sı iletimi yoluyla enjekte edilen plastiğin ısısını dağıtmak için yeterli değildir. Böylece, işlemin verimliliğini artırmak için, kalıp, her iki boşlukta yapılmış bir dizi içi boş kanal kullanılarak soğutulur ve bu sayede soğutma sıvısından daha iyi bir ısı alışverişi sağlanır. Plastik enjeksiyon kalıbının soğutma kanallarının tasarımı ile ilgili birkaç olasılık vardır (Mercado-Colmenero vd., 2018).

Kalıp tasarımı seçimi temel olarak üç faktöre bağlıdır: plastik parçanın geometrik özellikleri, kalıbın boyutu ve her bir soğutma sisteminin gerektirdiği üretim teknolojisi. Bu faktörler dikkate alınarak, soğutma sistemleri, parça geometrisine uyarlanmış geleneksel soğutma modelleri veya konformal sistemler aracılığıyla tasarlanabilir. Geleneksel sistemler, geleneksel işleme tekniklerini kullandıklarından, düşük üretim maliyetleri avantajına sahiptir. Bununla birlikte, yalnızca düz geometrili ve derin içbükeylikleri olmayan ince parçalarda sınırlı bir uygulamaları vardır. Geleneksel soğutma kanallarından farklı olarak konformal soğutma kanalları, parça ile temas halinde olan kalıp boşluklarının yüzeyi ile soğutma devresi arasında sabit bir mesafe bırakarak karmaşık yüzeylere sahip parçalarda hassas sıcaklık kontrolü elde edilmesini sağlar (Mercado-Colmenero vd., 2018).

Soğutma sistemi tasarımında, tasarım değişkenleri tipik olarak soğutma kanallarının boyutunu, konumunu, düzenini, soğutucunun termal özelliklerini, sıcaklığını ve akış hızını içerir. Bu kadar çok tasarım parametresi söz konusu olduğunda, optimum soğutma sistemini belirlemek için tasarım çalışmasını yapmak son derece zordur. Bu soğutma kanallarının tasarımında simülasyon programları kullanılmalıdır. Analiz sonuçlarının doğrulanması için deneysel çalışma da mutlaka yapılmalıdır. Ürün kalitesinin nümerik olarak tespit edilmesi çok da mümkün değildir. $\mathrm{Bu}$ yüzden malzemenin kalite gereksinimleri sağlanmıyorsa tekrarlı deneysel işlemler yapılmalıdır (Qiao 2006, Mercado-Colmenero vd., 2018).

Enjeksiyon kalıbı soğutma sistemleriyle ilgili birçok çalışma yapılmıştır ve bunlar CAE (Computer Aided Engineering) analizi, optimizasyon, özel üretim teknikleri ve akıllı tasarım e-ISSN: 2148-2683 araçları olmak üzere dört araştırma alanında sınıflandırılabilir. Wang vd., (1994) tarafindan yapılan ilk çalışmalar, esas olarak soğutma sistemlerinin CAE analizine odakland. Bu simülasyon analizleri MoldFlow ve Moldex 3D gibi, kalıp üretilmeden önce soğutma sistemlerinin performansını tahmin etmek için endüstride yaygın olarak kullanılan ticari paketlerle yapılmıştır (Li vd., 2012).

Literatürde özellikle soğutma kanallarının yerleşimi, tasarımı ve analizi ile ilgili yapılmış çalışmalar bulunmaktadır. Daha önce enjeksiyon kalıbı soğutma işlemleri ile ilgili deneysel araştırmalar da yapılmıştır (Turng ve Wang, 1990; Opolski ve Kwon, 1987). Bu çalışmalarda optimum çalışma şartları altında soğutma sisteminin tasarlanması dezavantajı vardır. Bu yüzden bazı yazarlar soğutma sistemlerinin tasarımı için otomasyon tasarımlarını araştırmışlardır. Li (2001), soğutma özelliklerinin tanınması için plastik parçada yeni bir programlama geliştirmiştir. Plastik parçanın karmaşık geometrisini anlaşııır kolay parçalara ayırmıştır. Her geometriye en uygun soğutma işlemini önermişlerdir. Li vd., (2005) çalışmasında soğutma sisteminin tasarım aşamasından kanalların dizilim aşamasına kadar olan kısmının otomasyon hesaplamalarını yapmışlardır. Mercado-Colmenero vd., (2018) yaptıkları çalışmada, soğutulacak plastik parçanın geometrisine dayanarak, soğutma sistemlerinin enjeksiyon kalıplarının tasarımında yeni bir metod geliştirmişlerdir. Malzemenin sağlıklı bir şekilde soğutulmasını sağlamak için işlevsel parametreleri dikkate alarak soğutma işleminin bir analizini gerçekleştirmişlerdir. Guan vd., (2019) enjekte edilen bir parça ile kalıbın yüzey pürüzlülüğü arasındaki etki durumunu araştırmışlardır. Ronkay ve vd., (2017) enjeksiyonla kalıplanmış numunelerin gözenekliliği ile kalıp sıcaklığı arasında ilişki olup olmadığını incelemişıerdir.

Soğutma sistemlerini optimize etmek için çeşitli teknikler geliştirilmiştir. Lam vd., (2004) soğutma kanallarının boyutunu, konumunu ve soğutma sistemlerinin işleme parametrelerini optimize etmek için bir genetik algoritma kullanan bir yöntem geliştirmiştir. Matsumori vd., (2006) soğutma kanallarının optimum şeklini belirlemek için soğutucu akışının etkisini hesaba katan bir teknik geliştirmişlerdir. Xu vd., (2001) özel imalat yöntemlerini kullanarak, soğutma kanalları ve kalıp yüzeyi arasında sabit bir mesafeyi koruyarak daha düzgün soğutma elde etmeyi amaçlayan yöntemler uygulamışlardır.

Tang vd., (1997) geçici soğutma analizine dayalı olarak optimum sistem tasarımı için bir yaklaşım sunmuşlardır. Tasarım kısıtlamaları ve amaç fonksiyonunu, sonlu elemanlar analizi kullanarak çözmüşlerdir. Tasarım duyarlılık analizi (DSA), son yıllarda optimum tasarım sürecinin önemli bir bileşeni olarak önem kazanmıştır (Qiao 2006). Modelin analiz çözümünde, optimum koşullara ulaşmak için doğru yöntem seçilmesi ekonomik kazanç sağlayabilir. Matsumoto ve Tanaka (1993), 1s1 iletimi problemleri için tasarım değişkenlerine göre bir analiz formülasyonu sunmuşlar ve bunu enjeksiyon kalıplarındaki soğutma kanallarının optimum tasarımına uygulamışlardır.

Literatürde bu alanda yapılan optimizasyon çalışmalarında özellikle CAE (Computer Aided Engineering), Moldflow, Moldex 3D gibi simülasyon programları kullanılmıştır. Optimizasyon çalışmasında Taguchi yaklaşımının ve Comsol programının birlikte kullanılması, diğer araştırmacılar tarafından yapılan çalışmalarla karşılaştırıldığında, bu çalışmanın yenilikçi yönünü ortaya koymaktadır. Çalışmada simülasyon metodu, enjeksiyon kalıbı soğutma sisteminin optimum tasarımı için uygulanmıştır. Ayrıca optimizasyon çalışmalarında akışkan 
debisi, yüzey pürüzlülük değeri ve kanal çapının soğuma süresi üzerindeki etkisi aynı anda incelenmemiştir. $\mathrm{Bu}$ çalışmada optimum koşulları bulmak için soğutucu akışkan debisinin $(2 \mathrm{lt} / \mathrm{dk}, 41 \mathrm{t} / \mathrm{dk}, 81 \mathrm{t} / \mathrm{dk})$, yüzey pürüzlülük değerinin $(0.025 \mathrm{~mm}$, $0.25 \mathrm{~mm}, 2.5 \mathrm{~mm})$ ve kanal çapının $(1 \mathrm{~cm}, 1.5 \mathrm{~cm}, 2 \mathrm{~cm})$ kalıp içerisinde bulunan poliüretan kaplı araç direksiyonunun soğutulması sürecine etkisi incelenmiştir.

\section{Materyal ve Metod}

\subsection{Boru İçi Akıș Denklemleri}

Soğutma kanalı içerisindeki kütle korunum ve momentum denklemleri aşağıdaki gibi ifade edilebilir (Comsol, 2021).

$$
\begin{aligned}
& \frac{\partial A \rho}{\partial t}+\nabla(A \rho u)=0 \\
& \rho \frac{\partial u}{\partial t}=-\nabla \mathrm{p}-f_{D} \frac{\rho}{2 d_{h}} u|u|
\end{aligned}
$$

Burada $\mathrm{u}$ ortalama akışkanın hızı $(\mathrm{m} / \mathrm{s})$, A borunun kesit alanı $\left(\mathrm{m}^{2}\right), \rho$ akışkanın yoğunluğu $\left(\mathrm{kg} / \mathrm{m}^{3}\right), \mathrm{p}$ basınç $\left(\mathrm{N} / \mathrm{m}^{2}\right)$.

\subsubsection{Sürtünme Faktörü Hesabı}

Kanal içerisindeki sürtünme faktörünü $\left(f_{D}\right)$ hesaplamak için Churchill sürtünme modeli kullanılmaktadır. Bu model laminer akış, türbülanslı akış ve geçiş bölgesi için kullanılmaktadır. İzotermal olmayan boru akış arayüzeyi için Churchill sürtünme modeli eşitlik (3)'de verildiği gibi yazılabilir (Churchill, 1997).

$$
\begin{aligned}
& f_{D}=8\left[\left(\frac{8}{R e}\right)^{12}+(A+B)^{-1.5}\right]^{\frac{1}{12}} \\
& \mathrm{~A}=\left[-2.457 \ln \left(\left(\frac{7}{R e}\right)^{0.9}+0.27(e / d)\right)\right]^{16} \\
& \mathrm{~B}=\left(\frac{37530}{\operatorname{Re}}\right)^{16} \\
& \operatorname{Re}=\frac{\rho u d}{\mu}
\end{aligned}
$$

\section{2 .Isı Transfer Denklemleri}

Soğutma kanalı için boru içerisindeki soğutma suyunun enerji denklemi;

$$
\rho A c_{p} \frac{\partial T}{\partial t}+\rho A c_{p} u \nabla T=\nabla A k \nabla T+f_{D} \frac{\rho A}{2 d_{h}}|u|^{3}+Q_{\text {wall }}
$$

şeklinde yazılabilir. Burada $c_{p}$ akışkanın özgül 1sısı (J/kgK), T soğutma suyunun sıcaklığı $(\mathrm{K})$, k 1 sı iletim katsayısı $(\mathrm{W} / \mathrm{mK})$, $Q_{\text {wall }}(\mathrm{W} / \mathrm{m})$ çevresinde kalıp bloğuna olan 1sı değişimi miktarıdır (Comsol, 2021).

Katı bloğundaki ve kalıplanmış poliüretan kısmındaki 1S1 transferi denklemi aşağıdaki gibi yazılmaktadır.

$\rho c_{p} \frac{\partial T_{2}}{\partial t}=\nabla k \nabla T_{2}$

Burada $\mathrm{T}_{2}$ katı sıcaklığ $(\mathrm{K}), \mathrm{k}$ katının 1sı iletim katsayısı (W/mK), $\rho$ katının yoğunluğu $\left(\mathrm{kg} / \mathrm{m}^{3}\right)$ ve $c_{p}$ katının özgül 1sısıdır $(\mathrm{J} / \mathrm{kgK})$. İki eşitlikten faydalanılarak boru içerisindeki akışkandan kalıp bloğuna olan 1Sı değişim miktarı $\left(Q_{\text {wall }}\right)$ eşitlik (9) yardımı ile hesaplanabilir (Comsol, 2021).

$$
Q_{\text {wall }}=\mathrm{hZ}\left(T_{\infty}-T\right)
$$

Burada $\mathrm{h}$ 1Sı taşınım katsayısı $\left(\mathrm{W} / \mathrm{m}^{2} \mathrm{~K}\right), \mathrm{Z}$ boru çevresi $(\mathrm{m})$ ve $T_{\infty}$ borunun dişındaki sıcaklık $(\mathrm{K})$ değeridir. $\mathrm{h}$ 1sı taşınım katsayısı Nusselt sayısı ve akışkanın termofiziksel özelliklerine bağlı olarak eşitlik (10)'da verildiği gibi hesaplanır (Incropera ve DeWitt, 2001).

$h=N u \frac{k}{d_{h}}$

Burada k akışkanın 1sı iletim katsayısı (W/mK), Nu Nusselt sayısı, $d_{h}$ hidrolik çap $(\mathrm{m})$. Eğer akış laminer ise dairesel kanal içi hesabında $\mathrm{Nu}=3.66$, türbülanslı ise Nusselt sayısı,

$N u=\frac{\left(f_{D} / 8\right)(R e-1000) \operatorname{Pr}}{1+12.7\left(f_{D} / 8\right)^{1 / 2}\left(\operatorname{Pr}^{2 / 3}-1\right)}$

$\mathrm{Bu}$ şekilde yazılabilir. Burada verilen Prandtl sayısı eşitlik (12) yardımı ile hesaplanabilir (Incropera ve DeWitt, 2001).

$\operatorname{Pr}=\frac{c_{p \mu}}{k}=\frac{\gamma}{\alpha}$

\subsection{Doğal Taşınım Denklemleri}

Kalıptan aynı zamanda dış ortama da doğal taşınım ile 1Sı transferi gerçekleşmektedir. Doğal taşınım akışkan hareketi içerisindeki kaldırma kuvvetleri ile oluşur. Kaldırma kuvveti akışkan içindeki yoğunluk farkından meydana gelir. Taşınım ile ortama aktarılan 1S1 transferi miktarı şu şekilde hesaplanmaktadır;

$$
Q=\mathrm{hA}\left(T_{y}-T_{\infty}\right)
$$

Burada h 1sı taşınım katsayısı $\left(\mathrm{W} / \mathrm{m}^{2} \mathrm{~K}\right)$, A yüzey alanı $\left(\mathrm{m}^{2}\right)$, $T_{y}$ yüzey sıcaklığı $(\mathrm{K})$ ve $T_{\infty}$ dış ortam sıcaklığı $(\mathrm{K})$. Isı taşınım katsayısını hesaplamak için Rayleigh boyutsuz sayısının hesaplanması gerekir. Rayleigh sayısı Grashof sayısı ile Prandtl boyutsuz sayılarının çarpımına eşittir. Kullanılan Grashof sayısı şu şekilde hesaplanmaktadır (Incropera ve DeWitt, 2001).

$G r=\frac{g \beta L_{k}{ }^{3}\left(T_{y}-T_{\infty}\right)}{\gamma^{2}} \quad R a=\operatorname{GrPr}$

Burada g yerçekimi ivmesi $\left(\mathrm{m}^{2} / \mathrm{s}\right), L_{k}$ karakteristik uzunluk (m) ve $\gamma$ kinematik viskozite $\left(\mathrm{m}^{2} / \mathrm{s}\right)$. Rayleigh sayısının aralığına göre Nusselt sayısı elde edilir. Dikey levhada Rayleigh değerleri için Churchill ve Chu tarafindan önerilen bağıntılar aşağıda verilmiştir (Incropera ve DeWitt, 2001).

$$
\begin{aligned}
& N u=0.68+\frac{0.670 R a^{1 / 4}}{\left[1+(0.492 / P r)^{9 / 16}\right]^{4 / 9}} \quad R a \leq 10^{9} \\
& N u=0.825+\frac{0.387 R a^{1 / 6}}{\left[1+(0.492 / P r)^{9 / 16}\right]^{8 / 27}} \quad R a \geq 10^{9}
\end{aligned}
$$

Isı transferi miktarını hesaplamak için bilinmesi gereken 1S1 taşınım katsayısını hesaplamak için ise eşitlik (17) kullanılır (Incropera ve DeWitt, 2001).

$$
N u=\frac{h L_{k}}{k}
$$

Burada $L_{k}$ karakteristik uzunluk (m), k havanın 1s1 iletim katsayısı $(\mathrm{W} / \mathrm{mK}), \mathrm{h}$ doğal $1 \mathrm{~s} 1$ taşınım katsayısı $\left(\mathrm{W} / \mathrm{m}^{2} \mathrm{~K}\right)$. 
Burada dikey levha için karakteristik uzunluk $\left(L_{k}\right)$ levhanın uzunluğu alınır.

Ortamdaki akışkana göre sıcak veya soğuk dikey levhada yerçekimi kuvveti levha ile aynı doğrultudadır. Yoğunluk farkından dolayı kaldırma kuvveti akışkan hareketini aşağıya veya yukarıya doğru yönlendirir. Eğer levha yatay ise kaldırma kuvveti yüzeye dik yöndedir. Akışın 1sı geçişi ve biçimi yüzeyin aşağıya veya yukarıya bakmasına, 1sıtılyor veya soğutuluyor olmasına bağlıdır. Yatay yüzeyler için McAdams, (1954) tarafindan önerilen bağıntı kullanılmaktadır. Burada karakteristik uzunluğun tanımı şu şekilde yapılmaktadır;

$L_{k}=\frac{A}{C}$

Burada A levha yüzey alanı $\left(\mathrm{m}^{2}\right)$, Ç çevre uzunluğu (m). Isıtılan bir levhanın üst yüzeyi veya soğutulan bir levhanın alt yüzeyi için;

$N u=0.54 R a^{1 / 4} \quad 10^{4} \leq R a \leq 10^{7}$

$N u=0.15 R a^{1 / 3} \quad 10^{7} \leq R a \leq 10^{11}$

Eşitlikleri kullanılır. Isıtılan bir levhanın alt yüzeyi veya soğutulan bir levhanın üst yüzeyi için;

$N u=0.27 R a^{1 / 4} \quad 10^{5} \leq R a \leq 10^{10}$

Eşitliği kullanılır (Incropera ve DeWitt, 2001).

\subsection{Taguchi Analiz Denklemleri}

Maksimum, minimum ve nominal performans değerleri için eşitlik (22), (23) ve (24) kullanılmaktadır (Taguchi, 1990).

$\mathrm{S} / \mathrm{N}_{\max }=-10 \log \left(\frac{1}{n} \sum_{i=1}^{n} \frac{1}{y_{i}^{2}}\right)$

$\mathrm{S} / \mathrm{N}_{\min }=-10 \log \left(\frac{1}{n} \sum_{i=1}^{n} y_{i}^{2}\right)$

$\mathrm{S} / \mathrm{N}_{\text {nom }}=10 \log \left(\frac{\bar{y}^{2}}{s^{2}}\right)$

$\bar{y}=\frac{1}{n} \sum_{i=1}^{n} y_{i} \quad s^{2}=\frac{1}{n-1} \sum_{i=1}^{n}\left(y_{i}-\bar{y}\right)^{2}$

Burada $\mathrm{n}$ bir denemedeki test sayısı, $y_{i}$ performans karakteristikleri için gözlenen deneysel verinin i. değeri, $\bar{y}$ gözlem değerlerinin ortalaması ve $s^{2}$ gözlem değerlerinin varyansidir.

Simülasyondan elde edilen veriler Taguchi yöntemi ile yapılan analiz sonucunda ayn zamanda tahmin edilebilir.

$\mathrm{S} / \mathrm{N}^{\prime}=\mathrm{S} / \mathrm{N}_{a v g}+\sum_{i=0}^{p}\left(\mathrm{~S} / \mathrm{N}_{i}-\mathrm{S} / \mathrm{N}_{a v g}\right)$

Burada; $\mathrm{S} / \mathrm{N}^{\prime}$ tahmini $\mathrm{S} / \mathrm{N}$ oran1, $\mathrm{S} / \mathrm{N}_{\text {avg }}$ tüm $\mathrm{S} / \mathrm{N}$ oranlarının ortalaması, $\mathrm{p}$ faktör sayısı, $\mathrm{S} / \mathrm{N}_{i}$ her bir faktörün optimum seviyedeki S/N oranıdır.

Hesaplanan tahmini S/N' oranı eşitlik (27)'de kullanılarak optimum analiz kombinasyonu için tahmini ölçüm sonuç değeri elde edilir. Daha sonra bu değer ile simülasyon sonucu karşılaştırılarak, Taguchi analizi ile simülasyon sonuçlarının uyumlu olup olmadığı araştırılabilir.

Tahmin edilen de ğer $=10^{-\frac{\mathrm{S} / \mathrm{N}^{\prime}}{20}}$

\subsection{Model Geometrisi ve A $\breve{g}$ Yapısı}

Analizde kullanılan kalıp soğutulmasında kullanılan model $(0.5 \mathrm{~m} \times 0.15 \mathrm{~m} \times 0.15 \mathrm{~m})$ ve ă yapısı Şekil 1 'de verilmiştir. Kalıp ilk sıcaklığı 473.15K ve akışkanın giriş sıcaklığı 293.15K olarak kabul edilmiştir. Kalıp malzemesi alüminyum ve direksiyonun kaplama malzemesi olarak ise Poliüretan seçilmiştir. Analizlere başlamadan önce ağdan (mesh) bağımsızlık çalışması yapılmıştır. 97708 ağ sayısında \%1 in altında değere ulaşıldığ için 89354 ă̆ sayısı analizlerde kullanılmıştır (Çizelge 1). Malzemelerin termofiziksel özellikleri Çizelge 2'de verilmiştir.

\begin{tabular}{|c|c|c|}
\hline $\begin{array}{c}\mathrm{Ag}(\mathrm{mesh}) \\
\text { sayıs1 }\end{array}$ & 89354 & 97708 \\
\hline $\begin{array}{c}\text { Sicaklık } \\
\left({ }^{\circ} \mathrm{C}\right)\end{array}$ & 55.70 & 55.77 \\
\hline
\end{tabular}

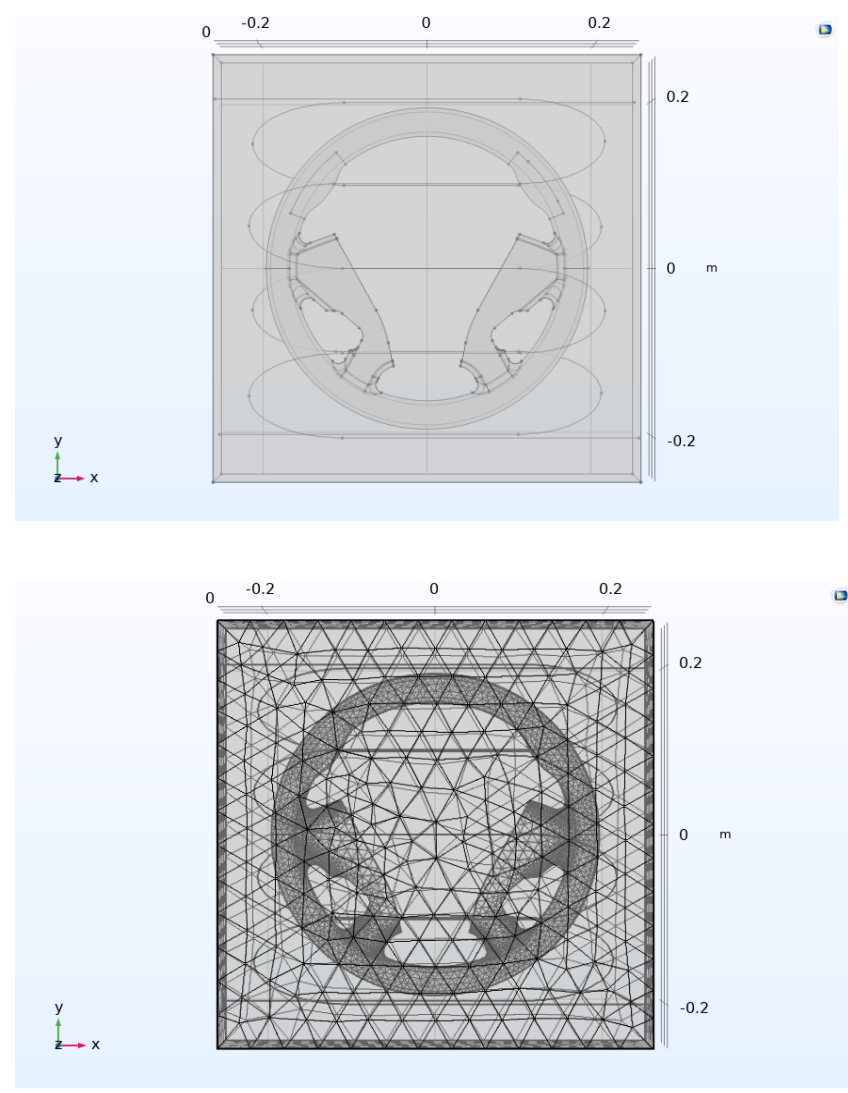

Şekil 1. Ürün geometrisi ve ăg yapısı

Çizelge 2. Malzemelerin termofiziksel özellikleri

\begin{tabular}{|c|c|c|c|}
\hline & $\begin{array}{c}\text { Özgül } \\
1 \mathrm{S1} \\
(\mathrm{J} / \mathrm{kgK})\end{array}$ & $\begin{array}{c}\text { Yoğunluk } \\
\left(\mathrm{kg} / \mathrm{m}^{3}\right)\end{array}$ & $\begin{array}{c}\text { Is1 iletim } \\
\text { katsay1s1 } \\
(\mathrm{W} / \mathrm{mK})\end{array}$ \\
\hline Alüminyum & 904 & 2700 & 237 \\
\hline Poliüretan & 1540 & 1250 & 0.32 \\
\hline
\end{tabular}




\section{Araştırma Sonuçları ve Tartışma}

\subsection{Taguchi Analizi Sonuçları}

Bu çalışmada kalıp soğutma sürecine etki eden parametreleri (yüzey pürüzlülük değeri, akışkan debisi ve kanal çapı) optimize etmek için Taguchi metodu kullanıldı. Analizlerde soğutucu akışkanın debileri $2 \mathrm{lt} / \mathrm{dk}$, $4 \mathrm{lt} / \mathrm{dk}$ ve $8 \mathrm{lt} / \mathrm{dk}$, yüzey pürüzlülük değerleri $0.025 \mathrm{~mm}, 0.25 \mathrm{~mm}$ ve $2.5 \mathrm{~mm}$, soğutucu kanal çapları ise $1 \mathrm{~cm}, 1.5 \mathrm{~cm}$ ve $2 \mathrm{~cm}$ alınmıştır (Çizelge 3). Enjeksiyon kalıplı plastiğin soğutulması parametrelerinin seviyelerini temsil eden örneklerin sayısal değerleri ve Taguchi L9 ortogonal dizi kullanılarak seçilen simülasyon sırası Çizelge 4'da ifade edilmiştir. Burada verilen değerler Minitab programına girilmiştir. 9 farklı değer ile Taguchi analizi gerçekleştirilmiştir. Analizler direksiyonun ortalama sıcaklığının 300K'e ulaşma süresi dikkate alınarak yapıldı. Ortalama sıcaklığın 300K'e ulaşma süresi minimum amaç fonksiyonu olarak tanımlandı.

Çizelge 3. Çalışmada kullanılan soğutma parametreleri ve seviyeleri

\begin{tabular}{ccccc}
\hline Parametre & $\begin{array}{c}\text { Serbestlik } \\
\text { derecesi }\end{array}$ & Level 1 & Level 2 & Level 3 \\
\hline $\begin{array}{c}\text { Pürüzlülük } \\
\text { (mm) }\end{array}$ & 2 & 0.025 & 0.25 & 2.5 \\
Debi (lt/dk) & 2 & 2 & 4 & 8 \\
Kanal çap1 & 2 & 1 & 1.5 & 2 \\
$\quad(\mathrm{~cm})$ & & & & \\
Toplam & 6 & & & \\
SD & & & & \\
\hline
\end{tabular}

Çizelge 4. Taguchi ortogonal L9 dizisi kullanılarak seçilen parametreler ve seviyeleri

\begin{tabular}{ccccc}
\hline $\begin{array}{c}\text { Ortogonal } \\
\text { dizi }\end{array}$ & Analiz no & $\begin{array}{c}\text { Pürüzlülük } \\
\text { değeri }\end{array}$ & Debi & $\begin{array}{c}\text { Kanal } \\
\text { çap1 }\end{array}$ \\
\hline 111 & 1 & 0.025 & 2 & 1 \\
122 & 2 & 0.025 & 4 & 1.5 \\
133 & 3 & 0.025 & 8 & 2 \\
212 & 4 & 0.25 & 2 & 1.5 \\
223 & 5 & 0.25 & 4 & 2 \\
231 & 6 & 0.25 & 8 & 1 \\
313 & 7 & 2.5 & 2 & 2 \\
321 & 8 & 2.5 & 4 & 1 \\
332 & 9 & 2.5 & 8 & 1.5 \\
\hline
\end{tabular}

\subsubsection{Soğutma için Optimizasyon Çalışması}

Plastik enjeksiyonlu direksiyonun soğutulması işleminde 9 farklı senaryoya ile hesaplanan soğuma süresi (saniye) verileri Minitab 18 programında Taguchi analiz modülüne girilmiştir. Sonrasında Taguchi analiz metodu kullanılarak ANOVA sonuçları elde edilmiştir. Çizelge 5 elde edilen soğuma süresi ve hesaplanan $\mathrm{S} / \mathrm{N}$ oran değerlerini göstermektedir. En küçük soğuma süresi değeri en büyük ortalama $\mathrm{S} / \mathrm{N}$ oranında elde edilmektedir. Şekil 2a'da hesaplanan ortalama S/N oranlarının analizine göre optimum koşul olan en az soğuma süresi, en büyük ortalama $\mathrm{S} / \mathrm{N}$ oranlarının elde edildiği $2.5 \mathrm{~mm}$ yüzey pürüzlülük değeri, akışkan debisi $81 \mathrm{t} / \mathrm{dk}$ ve kanal çapı $1 \mathrm{~cm}$ olarak elde edilmiştir. ANOVA metodu bize tüm etmenlerin önemini ve birbiri ile olan etkileşimlerini önceden incelememize imkan sağlar. Bu çalışmada parametrelerin birer birer katkısını elde etmek için ortalama $\mathrm{S} / \mathrm{N}$ değerlerini kullanarak ANOVA yöntemi incelendi. Çizelge 6'de verilen parametrelerin soğutma süresi üzerindeki etki oranları ile ANOVA sonuçları sunulmuştur. Bu yüzde oranları Şekil 2b'de ifade edilmiştir. Soğutma sonunda yüzey pürüzlülük etkisinin yaklaşık \%1, kanal çap1 etkisinin \%14 ve akışkan debisi etkisinin ise \%83 olduğu elde edilmiştir. $\mathrm{Bu}$ sonuca göre soğuma süresine etki eden parametrelerinin önem sırası akışkan debisi>kanal çapı>yüzey pürüzlülük değeri olarak elde edilmiştir. Soğutma sürecinde en önemli parametre akışkan debisidir. Çizelge 7'de $\mathrm{S} / \mathrm{N}$ oranı cevap sonuç tablosuna göre de en önemli (1 numaralı) parametrenin akışkan debisi oduğu görülmektedir. Kanal içi soğutmada en önemli parametrenin akışkan debisi olduğunu Türkan vd., (2020) parametrik çalışmalarında da elde etmişlerdir. En kısa sürede kalıp içerisindeki direksiyonun soğutulmasında akışkan debisi oldukça etkilidir.

Çizelge 5. Soğutma sürecindeki süre sayısı ve hesaplanan $S / N$ oranı

\begin{tabular}{cccc}
\hline $\begin{array}{c}\text { Ortogonal } \\
\text { dizi }\end{array}$ & Süre & $\begin{array}{c}\text { S/N } \\
\text { oran1 }\end{array}$ & $\begin{array}{c}\text { Standart } \\
\text { sapma }\end{array}$ \\
\hline 111 & 1500 & -63.5315 & 2.88675 \\
122 & 900 & -59.1138 & 2.64575 \\
133 & 650 & -56.2806 & 2.88675 \\
212 & 1600 & -64.0951 & 2.51661 \\
223 & 1000 & -60.0145 & 2.88675 \\
231 & 360 & -51.2464 & 5.00000 \\
313 & 2750 & -68.7867 & 5.00000 \\
321 & 550 & -54.8336 & 2.88675 \\
332 & 350 & -50.8820 & 5.00000 \\
\hline
\end{tabular}

Çizelge 6. Soğutma süresine ait $S / N$ oranlart için $A N O V A$ tablosu

\begin{tabular}{llllcc}
\hline Kaynak & DF & Seq SS & Adj SS & Adj MS & F \\
\hline $\begin{array}{l}\text { Yüzey } \\
\text { pürüzlülük } \\
\text { değeri }\end{array}$ & 2 & 3.671 & 3.671 & 1.836 & 0.86 \\
$\begin{array}{l}\text { Akışkan } \\
\text { debisi }\end{array}$ & 2 & 243.365 & 243.365 & 121.682 & 57.6 \\
$\begin{array}{l}\text { Kanal çap1 } \\
\text { Residual }\end{array}$ & 2 & 42.244 & 42.244 & 21.122 & 9.91 \\
$\begin{array}{l}\text { Error } \\
\text { Total }\end{array}$ & 8 & 4.265 & 4.265 & 2.132 & \\
\hline
\end{tabular}

Çizelge 7. S/N oranı için stralama tablosu

\begin{tabular}{lccc}
\hline Level & Yüzey pürüzlülük değeri & Akışkan debisi & Kanal çap1 \\
\hline 1 & -59.64 & -65.47 & -56.54 \\
2 & -58.45 & -57.99 & -58.03 \\
3 & -58.17 & -52.80 & -61.69 \\
Delta & 1.47 & 12.67 & 5.16 \\
Rank & 3 & 1 & 2 \\
\hline
\end{tabular}




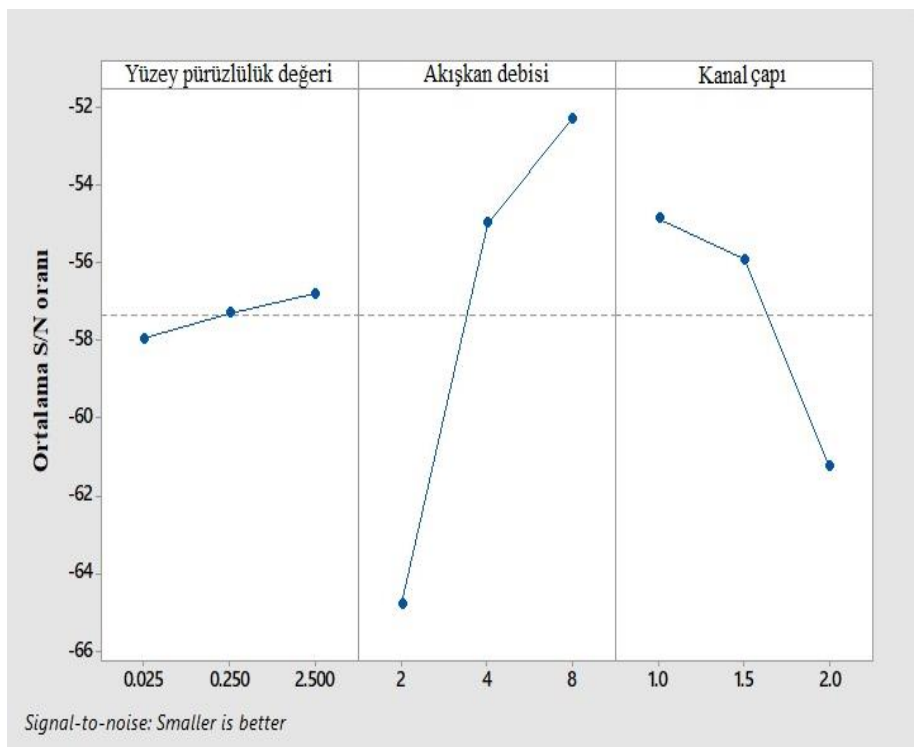

(a)

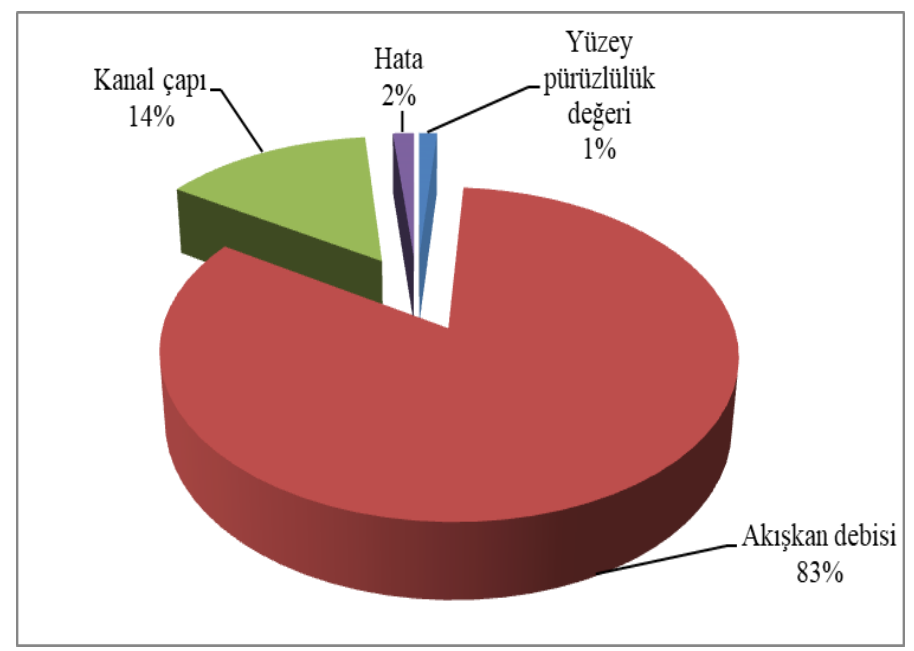

(b)

Şekil 2. a) Farklı soğutma parametreleri için soğuma süresinin $S / N$ oranı b) Parametrelerin soğuma süresi üzerindeki etki yüzdeleri

Optimizasyon işlemi sonuunda optimum koşul olarak elde edilen $2.5 \mathrm{~mm}$ yüzey pürüzlülük değeri, $8 \mathrm{lt} / \mathrm{dk}$ akışkan debisi ve $1 \mathrm{~cm}$ kanal çapı için tekrar analiz yapılmıştır. 60., 120. ve 240. saniyede kalıbın içinin, dışının, kanalların ve direksiyonun sicaklık değişiminin görsel simülasyon sonuçları Şekil 3-4-5'de verilmiştir. Başlangıçta soğutma suyunun sıcaklığı artarken direksiyon simidinde zamanla soğuma gerçekleştiği için bir süre sonra azalma görülmüştür. Direksiyonda hızlı soğuma soğutucu sıvının kanal içerisine girdiği kısımda gerçekleşmiştir. Soğutucu sıv1 120. saniyede $65^{\circ} \mathrm{C} 240$. saniyede $50^{\circ} C^{\prime}$ 'ye ulaşmıştır. Soğutmanın 120. saniyesinde direksiyonda homojen sicaklık dağılımı görülmemektedir. Ancak 240. saniyede malzemede homojen sıcaklık dağılımı gerçekleşmiştir.

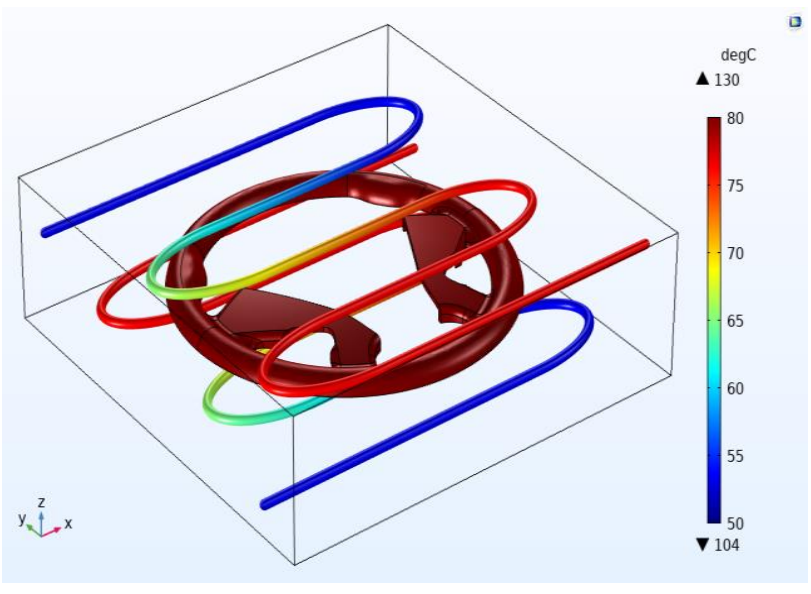

(a)

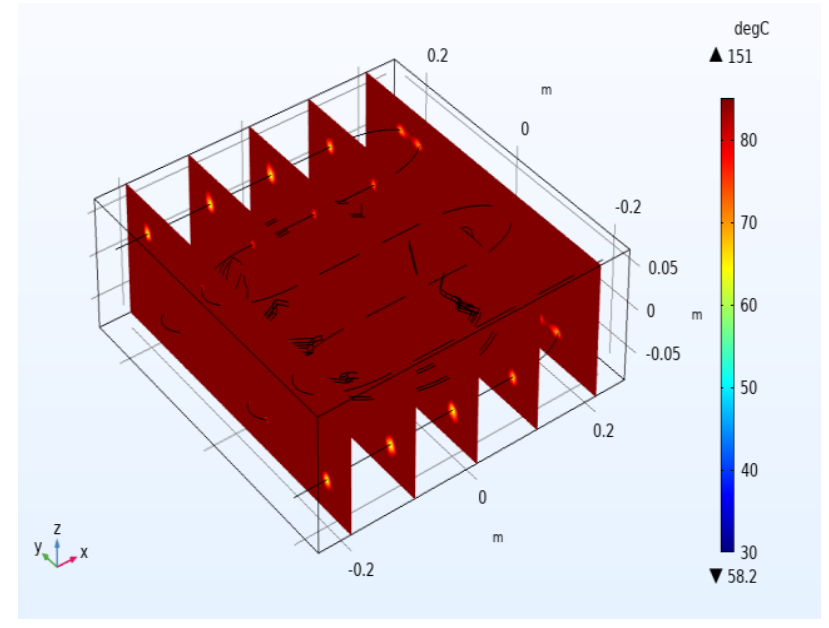

(b)

Şekil 3. 60. saniyede a) Kalıp içi kanal ve silindirin slcaklık değişimi b)Kalıbın sicaklık değişimi

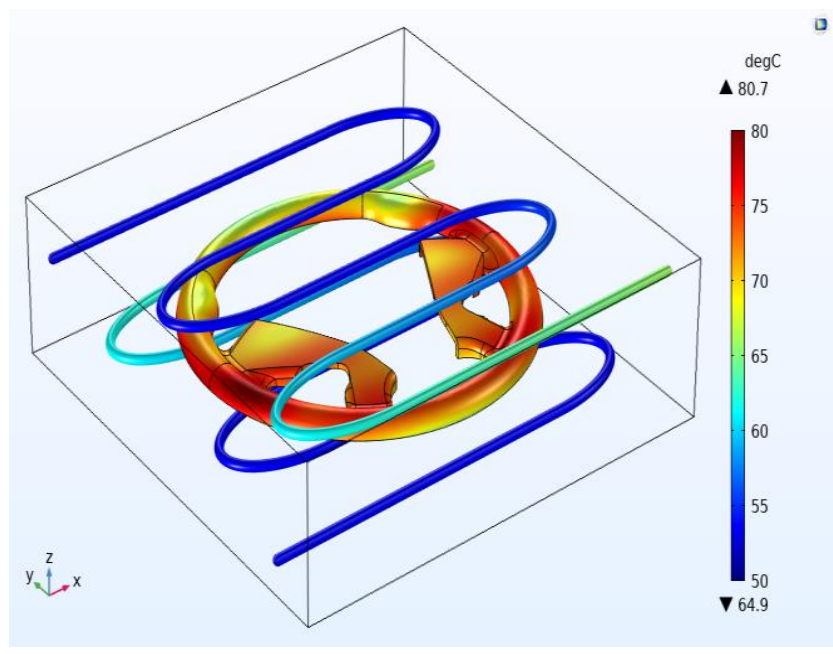

(a) 


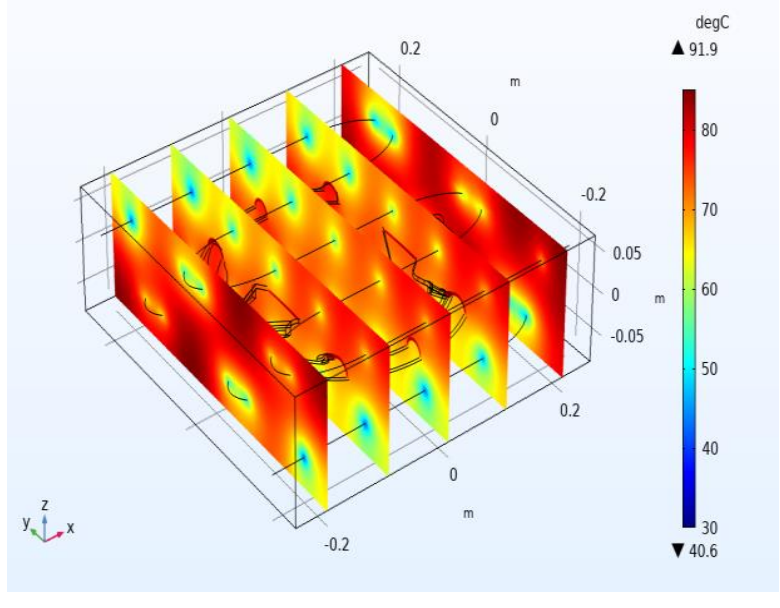

(b)

Şekil 4. 120. saniyede a) Kalıp içi kanal ve silindirin sıcaklık değişimi b)Kalıbın sıcaklık değişimi

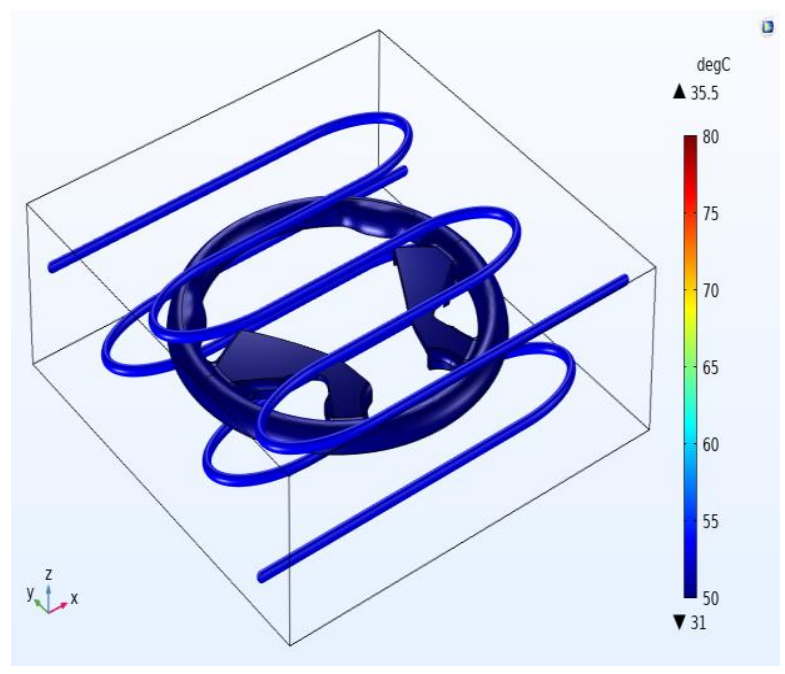

(a)

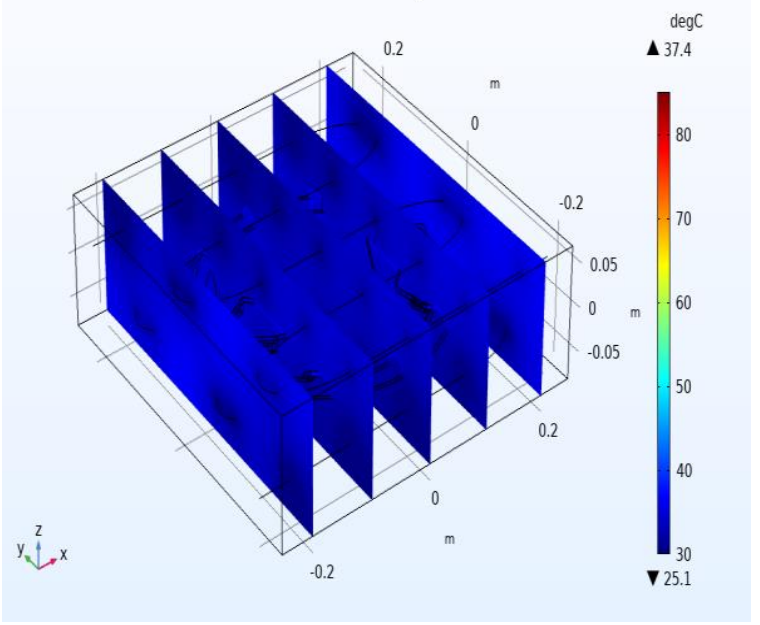

(b)

Şekil 5. 240. saniyede a) Kalıp içi kanal ve silindirin sicaklık değişimi b)Kalıbın sicaklık değişimi
Şekil 6'da poliüretan kaplı araç direksiyonunun soğutulması işlemi sırasında ortalama yüzey sıcaklığının süre ile değişim grafiği verilmiştir. Soğuma işleminin yaklaşık 300. Saniyesinde ortalama yüzey sıcaklığının $300 \mathrm{~K}$ e ulaştığı görülmektedir. Soğuma işleminin ilk 100 saniyesinde sıcaklık hızlı bir şekilde $100 \mathrm{~K}$ azalmıştır. Sonra soğuma işleminin yavaşladığ görülmektedir. Burada önemli olan homojen soğutmanın gerçekleştirilmesidir. Bu durumun gözlemlenebilmesi için ürün kesitininde analiz sonuçlarının görsel olarak incelenmesi gerekmektedir. Soğuma süresinin minimize edilmesi ürün kalitesinin artırılması ve homojen soğuma sağlanması açısından önemlidir ( Hassan vd., 2008).

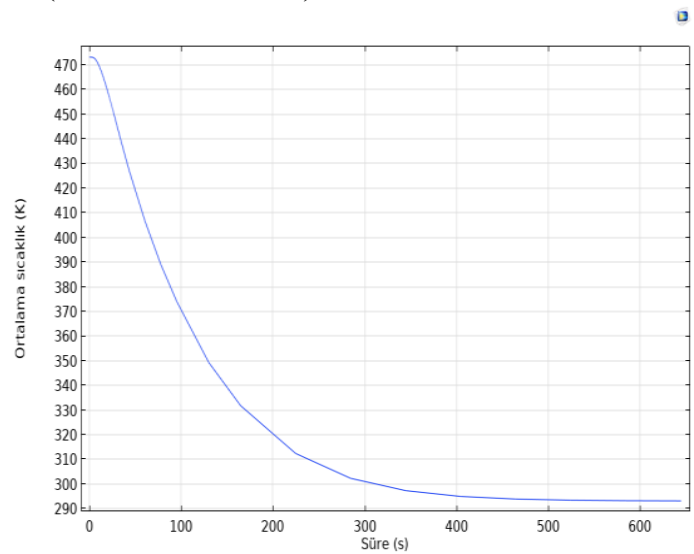

Şekil 6. Poliüretan kaplı direksiyonun ortalama yüzey sıcaklı̆̆ının süre ile değişimi

\subsection{Doğrulama Çalışması}

Simülasyondan elde edilen soğuma süresi Taguchi yöntemi ile yapılan analiz sonucunda aynı zamanda tahmin edilebilir. Çizelge 8'de tahmini S/N oranları kullanılarak optimum soğutma koşulu olan $2.5 \mathrm{~mm}$ yüzey pürüzlülük değeri, 81t/dk akışkan debisi ve $1 \mathrm{~cm}$ kanal çapı için Taguchi metodu kullanılarak elde edilen tahmini ve simülasyon değerleri verilmiştir. Simülasyon ve Taguchi metodu (tahmini değer) ile elde edilen değerlerin birbirine yakın olarak değiştiği görülmektedir.

\begin{tabular}{ccccc}
\multicolumn{5}{c}{ Çizelge 8. Sonuç çıtısına ait tahmini ve simülasyon değerleri } \\
\hline $\begin{array}{c}\text { Çıktı } \\
\text { değerleri }\end{array}$ & $\begin{array}{c}\text { Tahmini } \\
\text { Sahmini } \\
\text { değer } \\
\text { oranı }\end{array}$ & $\begin{array}{c}\text { Simülasyon } \\
\text { değeri }\end{array}$ & $\begin{array}{c}\text { Hata } \\
\text { oranı } \\
(\%)\end{array}$ \\
\hline $\begin{array}{c}\text { Soğuma } \\
\text { süresi } \\
\text { (saniye) }\end{array}$ & -50.00 & 327 & 320 & 2.14 \\
\hline
\end{tabular}

\section{Sonuç}

Bu çalışmada kalıp içi poliüretan kaplı araç direksiyonunun soğutulması için optimum koşullar ANOVA analizi yardımı ile araştırılmıştır. Soğutma parametreleri olarak akışkan debisi, yüzey pürüzlülük değeri ve kanal çapı alınmıştır. Taguchi analizi için seçilen 9 farklı analiz seti uygulanmıştır. Her bir analiz sonucu için soğutma süresi çıtı değerleri hesaplanmıştır. Minimum değerlere sahip olan soğutma süresi için optimum koşullar $2.5 \mathrm{~mm}$ yüzey pürüzlülük değeri, akışkan debisi $81 \mathrm{t} / \mathrm{dk}$ ve kanal çapı $1 \mathrm{~cm}$ olarak elde edilmiştir

Taguchi analizinden elde edilen sonuçların doğrulama çalışması yapıldı. Optimum soğutma koşuluna ait parametreler 
için analiz yapıldı. Analizden elde edilen çıktı değerleri ile Taguchi analizinden elde edilen tahmini değerler karşılaştırıldı ve sonuçların birbirine yakın olduğu görüldü. Bu sonuçlara göre Taguchi metodunun soğutma sürecinin optimizasyonun da uygun bir yaklaşım olduğu görülmüştür. Literatürde yüzey pürüzlülüğü için yapılan çalışmada Taguchi yönteminin etkili olduğu tespit edilmiştir. (Mersni vd., 2018).

Karmaşık optimizasyon problemleri ürün prototipi üretilmeden simülasyon programı yardımı ile hızlı ve maliyetsiz bir şekilde çözülebilir. Ayrıca bu durum çalışma koşullarına hızlı bir genel bakış sağlar. Modelleme için ayrıca değişken olarak çeşitli seçimler (çap, kanal sayısı, kanal düzeni, akışkan hızı, geometrik boyutlar, akışkan türleri, giriş sıcaklıkları vb.) oluşturulabilir.

Yapılan çalışma kalıp içi soğutma konusunun daha iyi anlaşılması için endüstriyel ve akademik kullanıcılara kolaylık sağlamıştır. Elde edilen sonuçlara göre kısa zamanda ürünün soğumasına etki eden parametrelerin yüzdesel değerleri kısa zamanda endüstriyel kullanıcılara sunulabilir. $\mathrm{Bu}$ çalışma endüstriyel kalıp içi ürün soğutma sistemlerinin imalatında ve ürünlerin optimum soğutma koşullarının tespit edilmesinde kullanılabilir. $\mathrm{Bu}$ sayede ürünün kalitesi artırılarak üretimde kullanılan enerjiden tasarruf edilmesi sağlanabilir. Bu şekilde deney için süre ve maliyetten tasarruf edilmiş olur. MercadoColmenero vd., (2018) üretim sürecinin verimliliğini artırmak ve maliyetlerini düşürmek için kalıp yüzey sıcaklığının düşürülmesinin önemli olduğunu ifade etmişlerdir.

$\mathrm{Bu}$ çalışmanın sonuçlarına göre enjekte edilen plastik kaplama malzemesinin soğutulması üzerinde en etkili parametrenin soğutma kanalının debisi olduğu tespit edilmiştir. Kanal içi yüzey pürüzlülük değeri ile akış debisinin artışı soğuma süresini azaltırken kanal çapındaki artış soğuma süresini uzatmıştır. Bunun nedeninin kanal çapının artmasının akışkanın hızını azaltarak 1S1 transferi miktarını düşürmesi olarak söylenebilir. $\mathrm{Bu}$ çalışmadan elde edilen sonuca benzer olarak, kanal çapının optimizasyon problemlerinde minimize edilmesi gerektiği vurgulanmıştır (Mercado-Colmenero vd., 2018). Yüzey pürüzlülügünün de kalıp tasarımında önemli bir parametre olduğu Guan vd., (2019) tarafından tespit edilmiştir.

\section{Kaynakça}

Churchill, S.W. (1997). Friction factor equations span all fluid flow regimes, Chem. Eng., vol.84, no. 24, p.91.

Comsol Multiphysics 5.3. (2021). Pipe Flow Module User's Guide, Heat Transfer Module.

Guan, B., Cherrill, M., Pai, J.H., Priest, C. (2019). Effect of mould roughness on injection moulded poly (methyl methacrylate) surfaces: Roughness and wettability, Journal of Manufacturing Processes, 48, pp.313-319. doi: 10.1016/j.jmapro.2019.10.024.

Hassan, H., Regnier, N., Lebot, C., Pujos, C., Defaye, G. (2008). Effect of cooling system on the polymer temperature and solidification during injection molding, Applied Thermal Engineering. doi: 10.1016/j.applthermaleng.2008.08.011.

Incropera, F.P., DeWitt, D.P. (2002). Fundamentals of Heat and Mass Transfer, 5th ed., John Wiley \& Sons, pp. 486-487.

Lam, Y.C., Zhai, L.Y., Tai, K., Fok, S.C. (2004). An evolutionary approach for cooling system optimization in plastic injection moulding. Int. J. of Pro. Research,42(10):2047-61,doi: 10.1080/00207540310001622412.
Li, C.L. (2001). A feature-based approach to injection mould cooling system design. Computer Aided Des., 33(14), pp.1073-90. doi: 10.1016/S0010-4485(00)00144-5.

Li, C. G., Li, C.L., Liu, Y., Huang, Y. (2012). A new C -space method to automate the layout design of injection mould cooling system, Comput Aided Des., 44:811-23. doi: 10.1016/j.cad.2012.01.005.

Li, C.L., Li, C.G., Mok, A.C.K. (2005). Automatic layout design of plastic injection mould cooling system, Computer-Aided Design, 37(7), pp.645-662. doi:10.1016/j.cad.2004.08.003.

Matsumori, T., Yamazaki, K., Matsui, Y. (2006). Optimization of cooling pipe system of plastic molding. In: IFIP international federation for information processing, system modeling and optimization, 199, 161-8. doi: 10.1007/0-38733006-2_15.

Matsumoto, T., Tanaka, M. (1993). Optimum design of cooling lines in injection moulds by using boundary element design sensitivity analysis, Finite Elements in Analysis and Design, 14:177-85.

Mersni, W., Boujelbene, M., Salem, S.B., Alghamdi, A.S. (2018). Optimization of the surface roughness in ball end milling of titanium alloy Ti-6Al-4V using the Taguchi Method. Procedia Manuf., 20:271-6. doi: 10.1016/j.promfg.2018.02.040.

McAdams, W.H., (1954). Heat Transmission, $3^{\text {rd }}$ ed., McGraw Hill, New York, Bölüm 7.

Mercado-Colmenero, J.M., Rubio-Paramio, M. A., MarquezSevillano, J.J., Martin-Doñate, C. A. (2018). New method for the automated design of cooling systems in injection molds, Computer-Aided Design, 104, pp.60-86. doi:10.1016/j.cad.2018.06.001.

Opolski, S.W., Kwon, T.W. (1987). Injection molding cooling system desig., In: ANTEC'86, pp. 264-8.

Qiao, H. (2006). A systematic computer-aided approach to cooling system optimal design in plastic injection molding, International Journal of Mechanical Sciences, 48(4):430-9. doi: 10.1016/j.ijmecsci.2005.11.001.

Ronkay, F., Molnar, B., Dogossy, G. (2017). The effect of mold temperature on chemical foaming of injection molded recycled polyethylene-terephthalate, Thermochimica Acta, 651, pp. 65-72. doi: 10.1016/j.tca.2017.02.013.

Taguchi, G. 1990. Introduction to quality engineering. Asian Productivity Organization, Tokyo.

Tang, L.Q., Chassapis, C., Manoochehri, S. (1997). Optimal cooling system design for multi-cavity injection molding. Finite Elements in Analysis and Design, 26:229-51.

Timur, M., Kılıç, H. (2021). Analysis of the Manufacturing Process Using Polyproplene by Plastic Injection Molding Method, European Journal of Science and Technology, (27), 832-836. doi: 10.31590/ejosat.993601.

Turng, L.S., Wang, K.K. (1990). A computer-aided cooling-line design system for injection molds, J Eng Ind-Trans ASME, 112(2), pp.161-167.doi: 10.1115/1.2899560.

Türkan, B., Etemoğlu, A. B., Çeğil, Ü. (2020). Poliüretan Kaplı Araç Direksiyonunun Soğutulmasının Simülasyonu, ElCezeri, 7 (2) , 592-602. doi: 10.31202/ecjse.681520.

Wang, K. K. (1994). Twenty years of CIMP research towards CAE for injection molding, Advances in Computer-Aided Engineering (CAE) of Polymer Processing, ASME, 1-5.

$\mathrm{Xu}, \mathrm{X}$., Sachs, E., Allen, S. (2001). The design of conformal cooling channels in injection molding tooling. Polymer Science and Engineering, 41(7), 1265-79. doi: 10.1002/pen.10827. 